\title{
Advances in bladder cancer imaging
}

\author{
Shaista Hafeez and Robert Huddart
}

\begin{abstract}
The purpose of this article is to review the imaging techniques that have changed and are anticipated to change bladder cancer evaluation. The use of multidetector 64-slice computed tomography (CT) and magnetic resonance imaging (MRI) remain standard staging modalities. The development of functional imaging such as dynamic contrast-enhanced MRI, diffusion-weighted MRI and positron emission tomography (PET)-CT allows characterization of tumor physiology and potential genotypic activity, to help stratify and inform future patient management. They open up the possibility of tumor mapping and individualized treatment solutions, permitting early identification of response and allowing timely change in treatment. Further validation of these methods is required however, and at present they are used in conjunction with, rather than as an alternative to, conventional imaging techniques.
\end{abstract}

Keywords: Bladder cancer, Diffusion-weighted MRI, Multidetector computed tomography, PET-CT, Staging, Ultrasound, Virtual cystoscopy

\section{Introduction}

Bladder cancer is a common disease with significant associated morbidity and mortality. Globally it is the ninth most common cause of cancer related death in men $[1,2]$. The clinical spectrum at presentation can be divided in to those with (i) superficial or non-muscle-invasive bladder cancer (NMIBC), approximately $70 \%$ to $80 \%$ of patients; (ii) muscle-invasive bladder cancer (MIBC), approximately $20 \%$ at presentation; and (iii) metastatic disease [3].

\section{The challenge}

Anatomically the bladder is divided into several layers. Accurate local staging with imaging is dependent on reliably distinguishing these layers. Clinical staging of the primary tumor is with bimanual examination under anesthesia. In those with MIBC this has been shown to be inaccurate in $23 \%$ to $50 \%$ of cases [4,5]. Transurethral resection of bladder tumor (TURBT) also understages tumors; approximately $30 \%$ to $50 \%$ patients are understaged at the time of cystectomy [6-10]. Therefore, accurate radiological correlation is important to help guide patient management.

The objective of any staging modality is to achieve adequate visualization of the primary tumor, extent of

\footnotetext{
* Correspondence: Robert.huddart@rmh.nhs.uk

The Royal Marsden NHS Foundation Trust and the Institute of Cancer Research, Sutton, Surrey, UK
}

(c) 2013 Hafeez and Huddart; licensee BioMed Central Ltd. This is an Open Access article distributed under the terms of the Creative Commons Attribution License (http://creativecommons.org/licenses/by/2.0), which permits unrestricted use, distribution, and reproduction in any medium, provided the original work is properly cited. loco regional disease and to determine the presence of metastases. However, conventional imaging modalities are unable to identify microscopic disease and can be inaccurate in identifying macroscopic disease. To address this newer imaging techniques are being explored to improve pretreatment staging, predict early response to treatment and provide non-invasive alternatives to cystoscopy for those requiring long-term surveillance. This article will review the development of imaging techniques that have changed, and are anticipated to change, bladder cancer evaluation.

\section{Computed tomography (CT)}

Multidetector (64-slice) CT scanning has provided the mainstay in radiological assessment. It has a reported sensitivity of $85 \%$ and specificity of $94 \%$ for the diagnosis of bladder cancers [11]. Detection is dependent on the morphology and size of the tumor. Flat lesions, carcinoma in situ (CIS), tumors less than $1 \mathrm{~cm}$ and in those whom recent resection has been performed, are more likely to be falsely negative $[5,11,12]$. Previous biopsy, inflammation, systemic chemotherapy and intravesical drugs also interfere with interpretation $[5,13]$.

CT remains the modality of choice for investigating hematuria and has replaced intravenous urogram (IVU) at most centers; its precise role in diagnosing bladder cancer is controversial. Although a 64-slice multidetector CT provides high spatial resolution allowing visualization 
of extravesical spread it is not reliable in determining the extent of locoregional disease [14]. It is limited by interobserver variability and inability to distinguish the muscle layers of the bladder [5,15].

\section{Ultrasound (US)}

US is at present not used routinely in clinical practice for the assessment of known bladder cancer, although the presence of hydronephrosis is suggestive of MIBC. It is however an important diagnostic tool in the investigation of hematuria in particular to assess large renal masses/ upper renal tracts. Bladder tumors may be visualized by ultrasound but a negative test does not exclude the presence of bladder cancer.

Two-dimensional transabdominal and transvaginal US have been investigated with regards to aiding bladder cancer staging but transurethral ultrasound has demonstrated the best ability to visualize depth of tumor penetration through the bladder wall $[16,17]$. Use of two-dimensional US is often limited by the subjectivity and expertise of the examiner. It is also unreliable in determining deeply infiltrating disease and nodal involvement [5]. Contrast-enhanced US (CE US) has been shown to be superior to conventional US in differentiating non-invasive and invasive bladder tumors $[18,19]$. Prior to TURBT CE US has a reported accuracy of $88.4 \%$ versus $72.1 \%$ compared to standard two-dimensional US, with 94.7\% sensitivity for tumors greater than $5 \mathrm{~mm}$; for lesions less than $5 \mathrm{~mm}$ sensitivity is reduced to $20 \%$ with a negative predictive value of $28.6 \%$ [18].

Three-dimensional US has been developed to provide reconstruction of the actual tumor with visualization of the bladder wall layers. The volume data can be retrieved and manipulated as if in real time, which increases objectivity, allows views in multiple planes to be obtained and improves the rate of primary bladder tumor diagnosis (88.9\% with two-dimensional US versus 100\% with three-dimensional US) when identifying $\mathrm{T} 3 \mathrm{~b}$ disease [20]. The disadvantage of this technique is that the entire tumor is not visualized and detection is particularly difficult when flat, plaque like tumors are present, there is coexistent calcification, the abdominal wall is rigid or the patient has central obesity [21].

Three-dimensional CE US uses enhanced images in three orthogonal planes and reflections of microbubbles to depict blood vessels. This has been shown to be clinically useful in differentiating MIBC and NMIBC [21]. Three-dimensional CE US may also have future role in assessing treatment response of the primary tumor to guide bladder-sparing approaches. Its use in assessing treatment has been evaluated other solid tumors including primary liver cancer following local therapy [22].
Although recent developments in US techniques overcome many of the limitations of two-dimensional US, they remain under investigation and have yet not translated in to widespread clinical use.

\section{Magnetic resonance imaging (MRI)}

MRI has excellent soft tissue resolution and multiplanar capabilities, which has made it an important staging modality for bladder cancer. Fundamental to its importance in local staging is the ability to manipulate image contrast by using different sequences. On T2-weighted images the bladder tumor is usually more conspicuous. The signal from perivesical fat can be suppressed using short tau inversion recovery (STIR) sequences, allowing signal from the tumor to be highlighted by suppressing signal from adjacent surrounding normal tissue [5,23,24].

In conjunction with gadolinium-containing contrast (Gd-Ca), MRI has an accuracy of $85 \%$ in differentiating NMIBC from MIBC and $82 \%$ accuracy in distinguishing organ confined disease from non-organ confined disease [25]. However, Gd-Ca should be avoided in those with renal impairment (estimated glomerular filtration rate (GFR) $<60 \mathrm{ml} /$ minute), as there is an increased risk of developing nephrogenic systemic fibrosis [26].

The clearest advantage of MRI over CT is the ability to determine the presence of muscle-invasive and extravesicle disease, and is our preferred modality of local staging prior to definitive radical treatment in MIBC.

The use of functional MRI imaging to provide biological information of tumor characteristics is under investigation. Dynamic contrast-enhanced MRI (DCE-MRI) enables in vivo assessment of tumor blood flow and permeability using paramagnetic contrast agents. Visualization of tumor blood flow can be used to identify areas of hypoxia and subsequently be used to predict treatment response [27]. It is an effective biomarker in predicting pathological complete response in those receiving primary chemotherapy for breast cancer and chemoradiotherapy for rectal cancer [23,28].

Intrinsic-susceptibility-weighted or blood-oxygenationlevel-dependent (BOLD) MRI, exploits the difference in magnetic susceptibility of oxyhemoglobin and deoxy hemoglobin. Deoxyhemoglobin is a paramagnetic molecule that allows it to act as an intrinsic contrast agent. BOLD MRI image acquisition during high oxygen concentration inhalation (carbogen, 95\% oxygen, 5\% carbon dioxide) reflects improved tumor oxygenation and blood flow and may help identify patients more likely to benefit from carbogen radiosensitization [29].

Diffusion-weighted MRI (DW MRI) is a functional imaging technique dependent on the inhibitory effect of cell membranes to the random motion of water molecules (Brownian motion) to generate image contrast by applying 
two equally sized but opposite diffusion sensitizing gradients, characterized by their b-values. As tumors have greater cellularity than normal tissue they demonstrate higher signal intensity (that is, restricted diffusion on MRI, reflected in the low mean apparent diffusion coefficient value $(\mathrm{ADC})$ ). This has the potential to provide both qualitative and quantitative information to aid tumor assessment. Histogram analysis of ADC through the entire tumor volume captures the diffusivity microenvironment and may aid identification of the heterogeneity known to exist within tumors that may have prognostic and predictive value [30-34].

DW MRI is also more accurate than T2-weighted MRI in staging both organ confined $(\leq \mathrm{pT} 2)(69.7 \%$ versus $15.1 \%$ ) and higher stage tumors (92.5\% versus $80.1 \%)$, with a reported sensitivity of $98.1 \%$ and positive predictive value of $100 \%$ [35]. There is also evidence that the ADC value may help identify high-grade tumors, with low ADC $\left(<1 \times 10^{-3} \mathrm{~mm}^{2} / \mathrm{s}\right)$ suggesting G3 disease [36].

Following treatment the ADC value increases, reflecting decreased cellularity, consistent with response. In other tumor types change in ADC has been used to identify and quantify early treatment response that may occur before conventional assessment of response is seen (for example, the Response Evaluation Criteria In Solid Tumors (RECIST) criteria), or where evaluation of morphological change is difficult to interpret [34,37-39]. DW MRI therefore has the potential for monitoring treatment response to chemotherapy or radiotherapy with identification of early non-responders who may benefit from change in treatment approach.

Conventional assessment of local response is with cystoscopy. One study has explored the role of DW MRI to assess response to chemoradiotherapy in 23 patients with MIBC. It demonstrated that the ADC was the only significant, independent predictor of chemoradiotherapy response with a sensitivity, specificity and accuracy of 92\%, 90\% and 91\% respectively. Consistent with other studies higher ADC was associated with unfavorable response [40].

Preliminary results for lymph node evaluation using DW MRI do not appear to be accurate (sensitivity $76.4 \%$, specificity $89.4 \%$, positive predictive value $86.6 \%$ and negative predictive value $71.4 \%$ ) [41].

The clinical use of functional MRI in bladder cancer assessment is not yet clearly defined but work to date suggests it likely to provide important information that may help guide treatment selection.

\section{Nanoparticle-enhanced MRI}

Involved lymph node detection by convention is governed by size and shape. Nodes greater than $1 \mathrm{~cm}$ are considered malignant on $\mathrm{CT}$ with a sensitivity of $85 \%$, specificity of $67 \%$, with a false negative rate of $21 \%$
[5,14]. However, enlarged reactive, non-malignant lymph nodes can mimic metastatic involvement with these modalities. Techniques that evaluate nodal function rather than morphology are aimed to more accurately characterize nodal disease.

Lymphotropic nanoparticle enhanced MRI exploits nodal macrophage function to detect metastases using ultra-small super-paramagnetic particles of iron oxide (USPIO) (ferumoxtran-10, Sinerem ${ }^{\circledR}$ ). After intravenous administration, the USPIO particles reach the lymph nodes via the lymphatics. Benign nodes have functioning macrophages, which phagocytose the USPIO causing them to accumulate within the node. This causes a drop in signal intensity on T2-weighted images. Metastatic lymph nodes that are partially or completely infiltrated are unable to take up these particles effectively. These nodal regions retain their signal intensity on T2-weighted images allowing detection on post-contrast imaging $[42,43]$.

Nodal enhancement is dependent on the tumor burden. Failure to detect microscopic foci of metastatic disease in very small lymph nodes leads to false negative results. False positives are due to reactive hyperplasia, localized nodal lipomatosis and insufficient USPIO [24]. Despite these limitations, the reported accuracy when evaluated prospectively in 58 patients prior to surgery is $95 \%$, with sensitivity of $96 \%$, specificity of $95 \%$, positive predictive value of $89 \%$ and a negative predictive value of $98 \%$ [44]. However, USPIO are no longer readily available, which limits the scope for further investigation and clinical application.

\section{Virtual cystoscopy (VC)}

Three-dimensional surface modeling is possible using cross sectional data obtained from CT or MRI, allowing indirect visualization of the mucosa and simulation of endoscopic evaluation. This method has been used to assess a number of other hollow organs including the colon and bronchus. Once source images are obtained, $\mathrm{VC}$ is performed on a dedicated workstation using a variety of computer algorithms [45-48].

Previous VC studies have focused on the potential diagnostic capability of evaluating hematuria. In a meta-analysis of 3084 patients from 26 studies to determine the validity of VC by CT, MRI or US, the pooled sensitivity for bladder cancer detection using $\mathrm{CT}$ virtual cystoscopy, magnetic resonance virtual cystoscopy and US was $93.9 \%, 90.8 \%$ and $77.9 \%$ respectively. The pooled specificity for bladder cancer detection was $98.1 \%, 94.8 \%$ and $96.2 \%$ respectively [49].

The advantage of this technique is that it is noninvasive, making it a potential alternative for those unable to tolerate conventional cystoscopy. It also allows visualization of areas that are difficult to access 
such as the bladder neck and mucosa within diverticulae. The disadvantages include inability to obtain pathology and low sensitivity in identifying smaller tumors $(<1 \mathrm{~cm})$, flat lesions and CIS $[24,46]$. Although VC is unlikely at present to replace conventional cystoscopy it may be considered in conjunction allowing the possibility of minimally invasive follow-up. Figure 1 illustrates appearance of tumor as seen on $\mathrm{VC}$ and on CT and MRI.

\section{Positron emission tomography (PET)} PET/CT: metabolic tracers

Composite PET/CT images provide three-dimensional whole body structural and functional information. The patient first moves through a spiral CT then a gamma camera in a single investigation. Radiotracers are used to identify the altered metabolic activity occurring within tumors. Metabolic change detectable by PET may precede anatomical changes on CT or MRI leading to greater
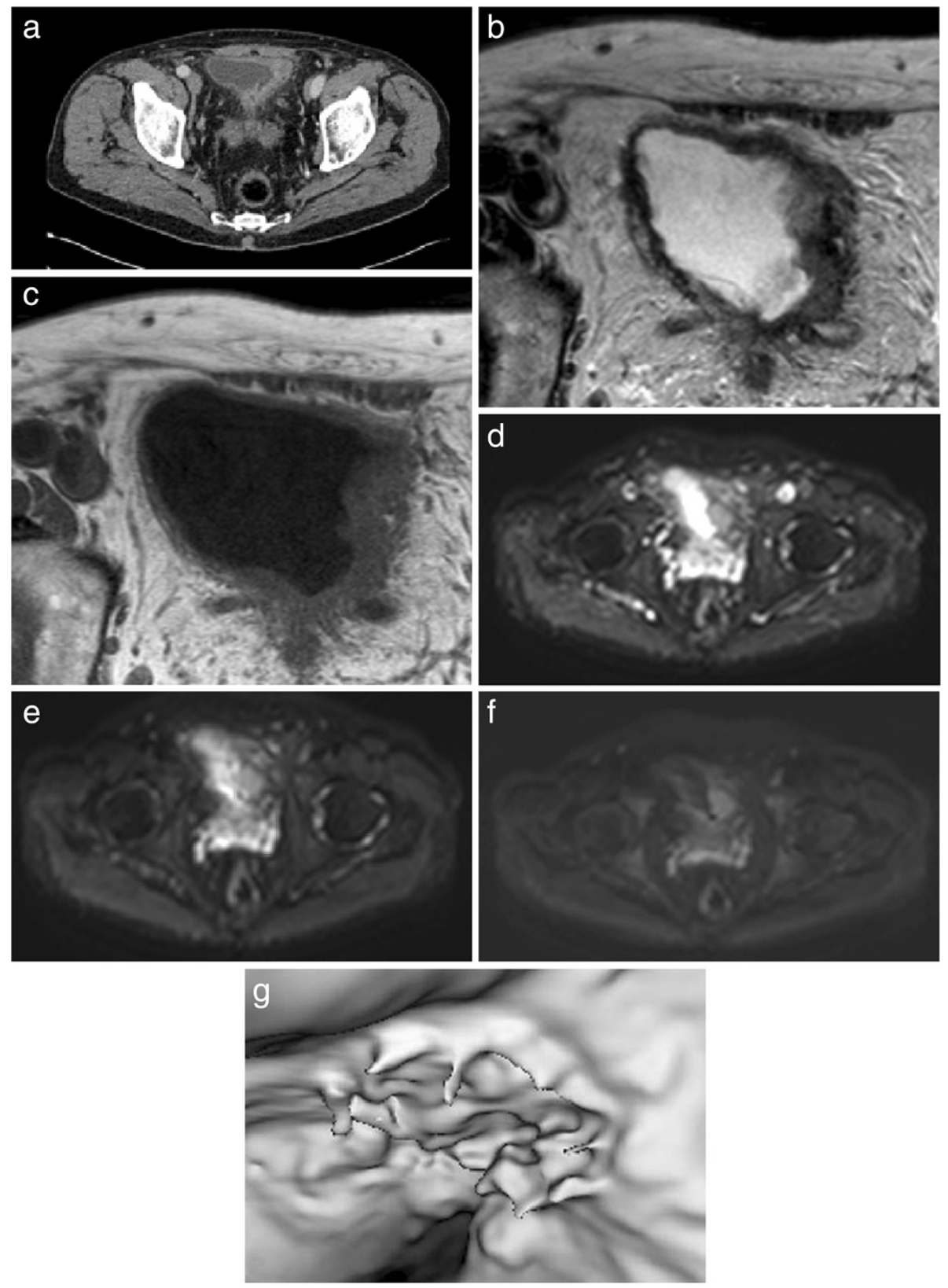

Figure 1 Patient with known T2 N0 Mo bladder cancer (left bladder wall): (a) contrast-enhanced computed tomography (CT) scan, (b) axial T2-weighted image performed on a 3 T magnetic resonance imaging (MRI) unit showing a hypointense lesion, (c) corresponding T1 image, (d) axial diffusion-weighted (DW) MRI at b-value 0, (e) axial DW MRI at b-value 100, (f) axial DW MRI at b-value 750, and (g) magnetic resonance virtual cystoscopy (MRVC) of same tumor with three-dimensional reconstruction of tumor bed showing opening into adjacent diverticulum. 
sensitivity as compared to conventional axial imaging alone. This uptake is quantified using the standardized uptake value (SUV). Uniform radiotracer distribution throughout the body produces a SUV of 1 [24].

${ }^{18}$ F-Flurodeoxyglucose (18-FDG) is currently the most commonly used PET tracer in oncological imaging and has an established role in the initial staging, response assessment and recurrence detection of many cancer types [50-53]. Its use is dependent on the increase glucose metabolism occurring within the tumor. However, it cannot distinguish between increased metabolic rate occurring as a result of infection, inflammation or the normal physiological activity in some organs [24].

The use of 18-FDG-PET in staging primary bladder disease, locally recurrent and perivesical nodal disease has been difficult because the interference caused by the urinary excretion of the isotope. A number of techniques encouraging adequate washout of 18-FDG from the urinary tract have been investigated to overcome this. These include elective voiding, catheterization, bladder irrigation, and forced diuresis with intravenous frusemide prior to delayed image acquisition [54-57].

Catheterization and irrigation prior to FDG-PET imaging has a reported $40 \%$ false positive rate for detection of recurrent or residual bladder cancer [57]. These measures are invasive, making them less acceptable to patients, and continuous bladder irrigation during image acquisition increases staff exposure to radiation [58].

In those whom FDG-urine washout was encouraged by diuretic injection, oral hydration and voiding, the sensitivity and specificity for FDG-PET CT was $86.7 \%$ and $100 \%$ respectively for detecting recurrent disease within the bladder [56]. Further investigation is necessary however to evaluate the impact of radiotherapy, endoscopic intervention and intravesical chemotherapy on FDG-PET interpretation within the bladder. When imaging is performed after chemotherapy the sensitivity decreases to $50 \%$ and therefore 18 -FDG PET results should be interpreted with caution following systemic treatment [59].

In a meta-analysis of the overall diagnostic accuracy of 18-FDG PET in bladder cancer, 6 studies involving 203 patients were assessed. The sensitivity and specificity of 18-FDG PET or PET/CT for staging or restaging (metastatic lesions) of bladder cancer was $82 \%$ and $89 \%$ respectively. The global measure of accuracy was 0.92 [60]. The limitations accepted by the authors include variation in the imaging technique used, one study used PET alone which meant anatomical accuracy because of the poor spatial resolution was lost, three studies were retrospective in nature and only two studies assessed detection of the primary tumor.

Although there is evidence that FDG PET-CT has a diagnostic role for identifying metastatic bladder disease, in our clinical practice it is not used as principal staging modality because of the limitations discussed above. In certain circumstances, however, it provides important contributory information when CT or MRI alone raises uncertainty regarding staging.

Alternative radiotracers that are dependent on cell proliferation, apoptosis, and angiogenesis, hypoxia and growth factors are also under investigation [61,62]. ${ }^{11} \mathrm{C}$-Choline and ${ }^{11} \mathrm{C}$-methionine are not excreted in the urine and may have role in future imaging of bladder cancer [24,54,63-65]. There is however limited data at present to support routine clinical use.

Choline is an essential component of cell membranes. Malignant tumors have a high turnover of cellular membranes representing their increased proliferation rate [66]. The normal bladder has low uptake with ${ }^{11} \mathrm{C}$-choline [63]. In the preoperative staging of 18 patients,

${ }^{11} \mathrm{C}$-choline was highly positive for primary and metastatic bladder cancer. Uptake was seen in all primary transitional cell carcinomas (mean SUV 7.3 \pm 3.2 SD). In six patients, ${ }^{11} \mathrm{C}$-choline uptake was seen in lymph nodes as small as $5 \mathrm{~mm}$; of those, four proceeded to surgery and three had pathological conformation of nodal disease [64].

${ }^{11} \mathrm{C}$-Choline has also been used to detect residual disease after TURBT. In a prospective study of 27

Table 1 A summary of imaging modalities and their current clinical role(s) in staging known muscle-invasive bladder cancer

\begin{tabular}{|c|c|}
\hline Technique & Description \\
\hline$C T$ & $\begin{array}{l}\text { Mainstay of assessment in locally advanced } \\
\text { and metastatic disease. Limitations are in } \\
\text { assessing primary tumor. }\end{array}$ \\
\hline US & $\begin{array}{l}\text { Two-dimensional techniques have no role } \\
\text { in routine assessment of primary tumor, } \\
\text { however presence of hydronephrosis is } \\
\text { suggestive of MIBC. Contrast-enhanced } \\
\text { and three-dimensional techniques are } \\
\text { under investigation. }\end{array}$ \\
\hline MRI & $\begin{array}{l}\text { Useful in identifying muscle-invasive and } \\
\text { extravesical disease. Functional MRI } \\
\text { currently under investigation as a predictive } \\
\text { tumor biomarker. }\end{array}$ \\
\hline Virtual cystoscopy & $\begin{array}{l}\text { Both CT and MRI data can be used to } \\
\text { reconstruct bladder mucosa and simulate } \\
\text { endoscopic evaluation. Unlike for other } \\
\text { tumor sites such as Gl, it is not used } \\
\text { routinely. }\end{array}$ \\
\hline PET-CT & $\begin{array}{l}\text { FDG-PET-CT not used as initial staging } \\
\text { modality. Often used in conjunction with } \\
\text { other imaging if uncertainly exists. FDG } \\
\text { use for staging local disease limited } \\
\text { predominantly by urinary excretion. } \\
\text { Alternative isotopes and receptor specific } \\
\text { molecules are under investigation. }\end{array}$ \\
\hline
\end{tabular}

$\mathrm{CT}$, computed tomography; FDG, flurodeoxyglucose; Gl, gastrointestinal; MIBC, muscle-invasive bladder cancer; MRI, magnetic resonance imaging; PET, positron emission tomography; US, ultrasound. 
patients prior to radical surgery, ${ }^{11} \mathrm{C}$-choline PET was comparable to $\mathrm{CT}$ alone for detecting residual cancer after TURBT but appeared to be superior for detecting nodal involvement, with reported sensitivity and specificity of $62.5 \%$ and $100 \%$ versus $50 \%$ and $68.4 \%$ for contrast-enhanced CT alone [65].

${ }^{11} \mathrm{C}$-Choline has a short half-life of approximately 20 minutes. Therefore clinical use is restricted predominantly to those centers with an on-site cyclotron. ${ }^{18} \mathrm{~F}$-choline analogs with greater half-lives have been developed to overcome this; however, significant urinary excretion occurs as compared to ${ }^{11} \mathrm{C}$-choline [67]. This represents a disadvantage for pelvic imaging as previously discussed unless adequate urinary washout can be encouraged.

${ }^{11} \mathrm{C}$-Methionine is a radiolabeled amino acid and is a potential tracer for visualizing protein metabolism, cellular proliferation and amino acid transport. Compared to 18-FDG PET in identifying primary tumors within the bladder, uptake is proportional to tumor stage, with a reported sensitivity of $78 \%$ in tumors greater than $1 \mathrm{~cm}$ but its value in local staging is not superior to conventional imaging [54].

${ }^{18} \mathrm{~F}$ Fluoride is a bone-seeking radiopharmaceutical that accumulates at sites of increased bone formation

Anticipated clinical pathway for staging of confirmed muscle invasive bladder cancer*
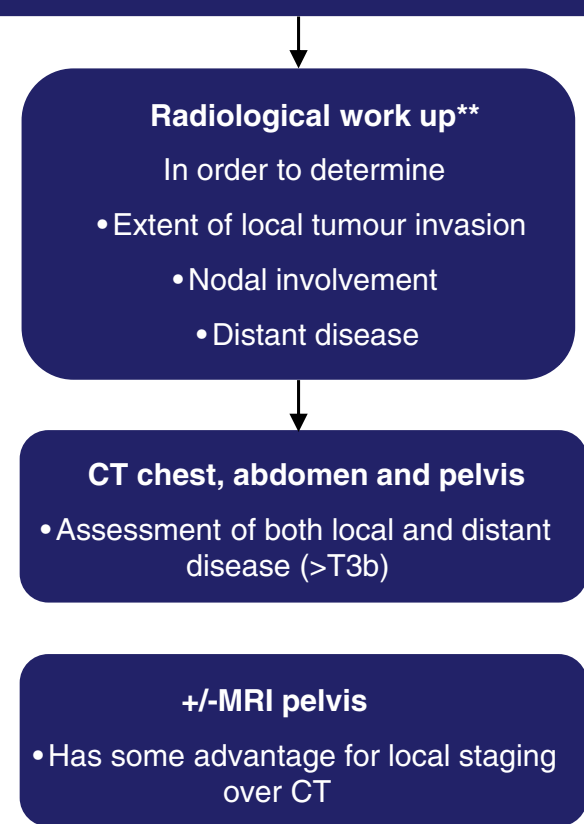

+/-FDG-PET

- No evidence for routine use

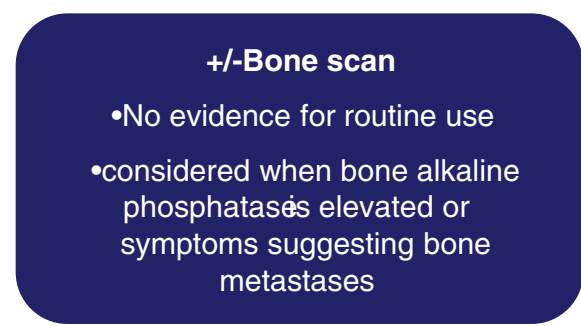

Recommendation based on well conducted trials without randomisation

Recommendation based on well conducted trials without randomisation

Recommendation based on meta-analysis of non randomised clinical trials

Figure 2 Anticipated clinical pathway for staging of confirmed muscle invasive bladder cancer. *Diagnostic investigations for haematuria differ from imaging to determine extent of local and distant disease in confirmed muscle invasive bladder cancer. **Based on European Association of Urology guidelines 2012, available at http://www.uroweb.org/guidelines/online-guidelines/ and http://www.nccn.org/professionals/ physician_gls/f_guidelines.asp\#site. 
reflecting increased osteoblastic activity occurring within metastases. It has been shown to have increased diagnostic accuracy as compared to technetium-99 m-methylene diphosphonate (99mTc-MDP) planar or single photon emission computed tomography (SPECT) in other solid tumors [68,69].

Non-FDG tracers are not in widespread clinical use partly because of the lack of robust evidence supporting clinical benefit but also because of their cost and limited availability.

\section{PET/CT: receptor specific radiopharmaceuticals}

Imaging biomarkers using PET-CT and radioimmunotherapy opens the possibility of an individualized therapeutic and imaging approach. The rationale is that a tumor specific target is combined with a therapeutic radioactive agent. The selective accumulation within the target tissue can then be visualized on PET. These imaging techniques have the potential to permit an image and treat approach' by allowing tumor staging, estimation of radiation dose distribution prior to therapy, and early monitoring of treatment response [70].

Commonly used nuclides in other tumors types include $\beta$ emitters such as ${ }^{131} \mathrm{I}$ and ${ }^{90} \mathrm{Y}$. They are attached to somatostatin receptor binding agents such as ${ }^{90}$ Y-DOTAd-Phe(1)-Tyr(3)-octreotide ( ${ }^{90}$ Y-DOTATOC) for the treatment of neuroendocrine tumors and to antibodies in ${ }^{131}$ I-tositumomab (Bexxar ${ }^{\circledR}$ ), ${ }^{90}$ Y-rituximab (Zevalin ${ }^{\circledR}$ ) to target the CD20 antigen on B cells for the treatment of lymphoma [70,71].

Overexpression and amplification of epidermal growth factor receptor (EGFR) (HER1 or ErdB1) and, or the HER2 gene is found in bladder cancers [72,73]. It therefore represents a potential target for both molecular imaging and therapy in those with known HER2-positive disease [61]. Monoclonal antibodies for example, trastuzumab labeled with ${ }^{18} \mathrm{~F}$, allows in vivo monitoring of HER2 expression by PET as well as assessing change in HER2 expression with therapy [74,75]. Trastuzumab has also been labeled with nucleotides suitable for therapy with the future possibility of treating metastatic disease and improving the outcome of those with HER2 bladder cancer $[70,76,77]$.

\section{PET/MRI}

Image acquisition with $\mathrm{PET} / \mathrm{CT}$ occurs sequentially rather than simultaneously. This means there is loss of temporal correlation, and additionally from the patient's perspective scanning time is significantly longer. The possibility of assessing different functional parameters using PET, DW MRI and combining that data with high-resolution anatomical information from MRI may provides new opportunities to study pathological and biochemical processes in vivo [78-81].
Most patients in the UK will present to urology teams via a 'one-stop hematuria clinic', where a two-dimensional US, urine cytology and flexible cystoscopy will be carried out. On the basis of these results a TURBT will be performed if appropriate. A CT scan will be undertaken where there is evidence of MIBC, high-grade NMIBC or suspicion of an upper tract lesion. However, in view of the evidence supporting MRI (as discussed above) our preferred practice is to stage local disease using this modality. A summary of imaging modalities and their current clinical role in staging known MIBC is presented in Table 1 and Figure 2.

\section{Patient perspectives}

Image acquisition time and tolerability of any proposed scan is important. CT image acquisition is usually within minutes but some research MRI protocols may take up to $1 \mathrm{~h}$. This can impact on patient compliance and predispose results to motion artifacts.

Use of MRI and US are free from ionizing radiation as compared to CT and PET/CT. At our institution a 64-slice multidetector CT scan of the chest, abdomen and pelvis is associated with radiation exposure of $16 \mathrm{mSv}$ during imaging; PET/CT is associated with exposure of $14 \mathrm{mSv}$ (PET component $8 \mathrm{mSv}$; $6 \mathrm{mSv}$ from a rapid image acquisition $\mathrm{CT}$ ). The clinical significance of these values in terms of inducing second malignancy is small in the context of the overall poor prognosis from muscleinvasive and metastatic bladder cancer at present. MRI scanning also does not require the use of iodine contrast agents that can induce reactions potentially anaphylactic in some individuals. In addition to allergy, intravenous contrast is also omitted for CT scanning in the presence of significant renal impairment.

Technology is rapidly changing so the ability to use this information to identify the most effective intervention for patients is critical. In the future we anticipate it will be routine to tailor a patient's treatment plan to both the physiological and physical characteristics of their disease, to monitor effectiveness of the intervention allowing a more dynamic approach to treatment.

\section{Conclusions}

Accurate staging is important in determining prognostic information and identifying appropriate treatment options. CT and MRI remain central to bladder cancer staging. The role of PET-CT using current tracers in staging and guiding management of bladder cancer remains to be defined. Future developments in functional imaging are likely to be important in predicting treatment response allowing timely identification of non-responders to guide appropriate change in treatment but further studies are required to determine which techniques or combination of techniques will optimize patient care. 


\section{Competing interests}

The authors declare that they have no competing interests.

\section{Authors' contributions}

$\mathrm{SH}$ drafted the manuscript. SH and $\mathrm{RH}$ revised the manuscript. Both authors read and approved the final version of the manuscript.

\section{Authors' information}

$\mathrm{RH}$ is a Reader at the Institute of Cancer Research (ICR), leading a team in the Division of Radiotherapy and Imaging that researches bladder and testicular cancer. He is also an Honorary Consultant in Urological Oncology at The Royal Marsden Hospital, where he manages and treats patients with urological cancer. SH is his Research Fellow at the ICR; together they are investigating image-guided (IGRT) and intensity-modulated radiotherapy (IMRT) for the treatment of muscle-invasive bladder cancer and the role that functional imaging plays in its management.

Received: 21 December 2012 Accepted: 14 March 2013 Published: 10 April 2013

\section{References}

1. UK Office for National Statistics: Mortality statistics EaW. [http://www.ons. gov.uk/ons/rel/cancer-unit/cancer-incidence-and-mortality/2008-2010/index. html]

2. Jemal A, Bray F, Center MM, Ferlay J, Ward E, Forman D: Global cancer statistics. CA Cancer J Clin 2011, 61:69-90.

3. Edge SB, Byrd DR, Compton CC, Fritz AG, Greene FL, Trotti A: (Eds): AJCC Cancer Staging Maual. 7th edition. New York, NY: Springer; 2010.

4. Jewett HJ, Strong GH: Infiltrating carcinoma of the bladder; relation of depth of penetration of the bladder wall to incidence of local extension and metastases. J Urol 1946, 55:366-372.

5. MacVicar AD: Bladder cancer staging. BJU Int 2000, 86(Suppl 1):111-122

6. Stein JP, Lieskovsky G, Cote R, Groshen S, Feng AC, Boyd S, Skinner E, Bochner B, Thangathurai D, Mikhail M, Raghavan D, Skinner DG: Radical cystectomy in the treatment of invasive bladder cancer: long-term results in 1,054 patients. J Clin Oncol 2001, 19:666-675.

7. Dutta SC, Smith JA Jr, Shappell SB, Coffey CS, Chang SS, Cookson MS: Clinical under staging of high risk nonmuscle invasive urothelial carcinoma treated with radical cystectomy. J Urol 2001, 166:490-493.

8. Ficarra V, Dalpiaz O, Alrabi N, Novara G, Galfano A, Artibani W: Correlation between clinical and pathological staging in a series of radical cystectomies for bladder carcinoma. BJU Int 2005, 95:786-790.

9. Mehrsai A, Mansoori D, Taheri Mahmoudi M, Sina A, Seraji A, Pourmand GH: A comparison between clinical and pathologic staging in patients with bladder cancer. Urol J 2004, 1:85-89.

10. Miladi M, Peyromaure M, Zerbib M, Saighi D, Debre B: The value of a second transurethral resection in evaluating patients with bladder tumours. Eur Urol 2003, 43:241-245.

11. Martingano P, Stacul F, Cavallaro M, Casagrande F, Cernic S, Belgrano M, Cova M: 64-Slice CT urography: 30 months of clinical experience. Radiol Med 2010, 115:920-935.

12. Wang LJ, Wong YC, Ng KF, Chuang CK, Lee SY, Wan YL: Tumor characteristics of urothelial carcinoma on multidetector computerized tomography urography. J Urol 2010, 183:2154-2160.

13. Kundra $V$, Silverman PM: Imaging in oncology from the University of Texas M. D. Anderson Cancer Center. Imaging in the diagnosis, staging, and follow-up of cancer of the urinary bladder. AJR Am J Roentgenol 2003, 180:1045-1054.

14. Paik ML, Scolieri MJ, Brown SL, Spirnak JP, Resnick MI: Limitations of computerized tomography in staging invasive bladder cancer before radical cystectomy. J Urol 2000, 163:1693-1696.

15. Tritschler S, Mosler C, Tilki D, Buchner A, Stief C, Graser A: Interobserver variability limits exact preoperative staging by computed tomography in bladder cancer. Urology 2012, 79:1317-1321.

16. Abu-Yousef MM, Narayana AS, Franken EA Jr, Brown RC: Urinary bladder tumors studied by cystosonography. Part I: Detection. Radiology 1984, 153:223-226.

17. Abu-Yousef MM, Narayana AS, Brown RC, Franken EA Jr: Urinary bladder tumors studied by cystosonography. Part II: Staging. Radiology 1984 153:227-231.
18. Nicolau C, Bunesch L, Peri L, Salvador R, Corral JM, Mallofre C, Sebastia C: Accuracy of contrast-enhanced ultrasound in the detection of bladder cancer. Br J Radiol 2011, 84:1091-1099.

19. Caruso G, Salvaggio G, Campisi A, Melloni D, Midiri M, Bertolotto M, Lagalla R: Bladder tumor staging: comparison of contrast-enhanced and gray-scale ultrasound. AJR Am J Roentgenol 2010, 194:151-156.

20. Park HJ, Hong SS, Kim JH, Kwon SB, Kwon KH, Choi DL, Park ST, Chang YW, Hwang JH: Tumor detection and serosal invasion of bladder cancer: role of three-dimensional volumetric reconstructed US. Abdom Imaging 2010, 35:265-270.

21. Li QY, Tang J, He EH, Li YM, Zhou Y, Zhang X, Chen G: Clinical utility of three-dimensional contrast-enhanced ultrasound in the differentiation between noninvasive and invasive neoplasms of urinary bladder. Eur J Radiol 2012, 81:2936-2942.

22. Xu HX, Lu MD, Xie XH, Xie XY, Kuang M, Xu ZF, Liu GJ, Wang Z, Chen LD, Lin MX: Treatment response evaluation with three-dimensional contrast-enhanced ultrasound for liver cancer after local therapies. Eur J Radiol 2010, 76:81-88.

23. Gollub MJ, Gultekin DH, Akin O, Do RK, Fuqua JL 3rd, Gonen M, Kuk D, Weiser M, Saltz L, Schrag D, Goodman K, Paty P, Guillem J, Nash GM, Temple L, Shia J, Schwartz LH: Dynamic contrast enhanced-MRI for the detection of pathological complete response to neoadjuvant chemotherapy for locally advanced rectal cancer. Eur Radio/ 2012, 22:821-831.

24. Saksena MA, Dahl DM, Harisinghani MG: New imaging modalities in bladder cancer. World J Urol 2006, 24:473-480.

25. Tekes A, Kamel I, Imam K, Szarf G, Schoenberg M, Nasir K, Thompson R, Bluemke D: Dynamic MRI of bladder cancer: evaluation of staging accuracy. AJR Am J Roentgenol 2005, 184:121-127.

26. Thomsen HS: Nephrogenic systemic fibrosis: history and epidemiology. Radiol Clin North Am 2009, 47:827-831.

27. Padhani AR, Husband JE: Dynamic contrast-enhanced MRI studies in oncology with an emphasis on quantification, validation and human studies. Clin Radiol 2001, 56:607-620.

28. Ah-See ML, Makris A, Taylor NJ, Harrison M, Richman Pl, Burcombe RJ, Stirling JJ, D'Arcy JA, Collins DJ, Pittam MR, Ravichandran D, Padhani AR: Early changes in functional dynamic magnetic resonance imaging predict for pathologic response to neoadjuvant chemotherapy in primary breast cancer. Clin Cancer Res 2008, 14:6580-6589.

29. Taylor NJ, Baddeley H, Goodchild KA, Powell ME, Thoumine M, Culver LA, Stirling JJ, Saunders MI, Hoskin PJ, Phillips H, Padhani AR, Griffiths JR: BOLD MRI of human tumor oxygenation during carbogen breathing. J Magn Reson Imaging 2001, 14:156-163.

30. Afaq A, Koh DM, Padhani A, van As N, Sohaib SA: Clinical utility of diffusion-weighted magnetic resonance imaging in prostate cancer. BJU Int 2011, 108:1716-1722.

31. Gerlinger M, Rowan AJ, Horswell S, Larkin J, Endesfelder D, Gronroos E, Martinez P, Matthews N, Stewart A, Tarpey P, Varela I, Phillimore B, Begum S, McDonald NQ, Butler A, Jones D, Raine K, Latimer C, Santos CR, Nohadani M, Eklund AC, Spencer-Dene B, Clark G, Pickering L, Stamp G, Gore M, Szallasi Z, Downward J, Futreal PA, Swanton C: Intratumor heterogeneity and branched evolution revealed by multiregion sequencing. N Engl J Med 2012, 366:883-892.

32. Barajas RF Jr, Rubenstein JL, Chang JS, Hwang J, Cha S: Diffusion-weighted MR imaging derived apparent diffusion coefficient is predictive of clinical outcome in primary central nervous system lymphoma. AJNR Am J Neuroradiol 2010, 31:60-66.

33. Pope WB, Kim HJ, Huo J, Alger J, Brown MS, Gjertson D, Sai V, Young JR, Tekchandani L, Cloughesy T, Mischel PS, Lai A, Nghiemphu P, Rahmanuddin S, Goldin J: Recurrent glioblastoma multiforme: ADC histogram analysis predicts response to bevacizumab treatment. Radiology 2009, 252:182-189.

34. Kyriazi S, Collins DJ, Messiou C, Pennert K, Davidson RL, Giles SL, Kaye SB, Desouza NM: Metastatic ovarian and primary peritoneal cancer: assessing chemotherapy response with diffusion-weighted MR imaging-value of histogram analysis of apparent diffusion coefficients. Radiology 2011, 261:182-192.

35. El-Assmy A, Abou-El-Ghar ME, Mosbah A, El-Nahas AR, Refaie HF, Hekal IA, El-Diasty $\mathrm{T}$, Ibrahiem el $\mathrm{H}$ : Bladder tumour staging: comparison of diffusion- and T2-weighted MR imaging. Eur Radiol 2009, 19:1575-1581.

36. Takeuchi M, Sasaki S, Ito M, Okada S, Takahashi S, Kawai T, Suzuki K, Oshima $H$, Hara M, Shibamoto Y: Urinary bladder cancer: diffusion-weighted MR 
imaging-accuracy for diagnosing $T$ stage and estimating histologic grade. Radiology 2009, 251:112-121.

37. Chen CY, Li CW, Kuo YT, Jaw TS, Wu DK, Jao JC, Hsu JS, Liu GC: Early response of hepatocellular carcinoma to transcatheter arterial chemoembolization: choline levels and MR diffusion constants-initial experience. Radiology 2006, 239:448-456.

38. Cui Y, Zhang XP, Sun YS, Tang L, Shen L: Apparent diffusion coefficient: potential imaging biomarker for prediction and early detection of response to chemotherapy in hepatic metastases. Radiology 2008, 248:894-900.

39. Harry VN, Semple SI, Gilbert FJ, Parkin DE: Diffusion-weighted magnetic resonance imaging in the early detection of response to chemoradiation in cervical cancer. Gynecol Oncol 2008, 111:213-220.

40. Yoshida S, Koga F, Kobayashi S, Ishii C, Tanaka H, Tanaka H, Komai Y, Saito K, Masuda H, Fujii Y, Kawakami S, Kihara K: Role of diffusion-weighted magnetic resonance imaging in predicting sensitivity to chemoradiotherapy in muscle-invasive bladder cancer. Int I Radiat Oncol Biol Phys 2012, 83:e21-7.

41. Papalia R, Simone G, Grasso R, Augelli R, Faiella E, Guaglianone S, Cazzato R, Del Vescovo R, Ferriero M, Zobel B, Gallucci M: Diffusion-weighted magnetic resonance imaging in patients selected for radical cystectomy: detection rate of pelvic lymph node metastases. BJU Int 2012, 109:1031-1036.

42. Harisinghani MG, Saini S, Hahn PF, Weissleder R, Mueller PR: MR imaging of lymph nodes in patients with primary abdominal and pelvic malignancies using ultrasmall superparamagnetic iron oxide (Combidex). Acad Radiol 1998, 5(Suppl 1):S167-S169.

43. Thoeny HC, Triantafyllou M, Birkhaeuser FD, Froehlich JM, Tshering DW, Binser T, Fleischmann A, Vermathen P, Studer UE: Combined ultrasmall superparamagnetic particles of iron oxide-enhanced and diffusionweighted magnetic resonance imaging reliably detect pelvic lymph node metastases in normal-sized nodes of bladder and prostate cancer patients. Eur Urol 2009, 55:761-769.

44. Deserno WM, Harisinghani MG, Taupitz M, Jager GJ, Witjes JA, Mulders PF, van de Kaa CA H, Kaufmann D, Barentsz JO: Urinary bladder cancer: preoperative nodal staging with ferumoxtran-10-enhanced MR imaging Radiology 2004, 233:449-456.

45. Beer A, Saar B, Rummeny EJ: Tumors of the urinary bladder: technique, current use, and perspectives of MR and CT cystography. Abdom Imaging 2003, 28:868-876.

46. Bernhardt TM, Schmidl H, Philipp C, Allhoff EP, Rapp-Bernhardt U: Diagnostic potential of virtual cystoscopy of the bladder: MRI vs $C T$. Preliminary report. Eur Radiol 2003, 13:305-312.

47. Tsili A, Tsampoulas C, Chatziparaskevas N, Silakos A, Kalef-Ezra J, Sofikitis N, Efremidis SC: Computed tomographic virtual cystoscopy for the detection of urinary bladder neoplasms. Eur Urol 2004, 46:579-585.

48. Lalondrelle S, Sohaib SA, Castellano IA, Mears D, Huddart R, Khoo V: Investigating the relationship between virtual cystoscopy image quality and CT slice thickness. Br J Radiol 2012, 85:1112-1117.

49. Qu X, Huang X, Wu L, Huang G, Ping X, Yan W: Comparison of virtual cystoscopy and ultrasonography for bladder cancer detection: a metaanalysis. Eur J Radiol 2011, 80:188-197.

50. Antoch G, Saoudi N, Kuehl H, Dahmen G, Mueller SP, Beyer T, Bockisch A, Debatin JF, Freudenberg LS: Accuracy of whole-body dual-modality fluorine-18-2-fluoro-2-deoxy-D-glucose positron emission tomography and computed tomography (FDG-PET/CT) for tumor staging in solid tumors: comparison with CT and PET. J Clin Oncol 2004, 22:4357-4368

51. Freudenberg LS, Antoch G, Schutt P, Beyer T, Jentzen W, Muller SP, Gorges R, Nowrousian MR, Bockisch A, Debatin JF: FDG-PET/CT in re-staging of patients with lymphoma. Eur J Nucl Med Mol Imaging 2004, 31:325-329.

52. Lardinois D, Weder W, Hany TF, Kamel EM, Korom S, Seifert B, von Schulthess GK, Steinert HC: Staging of non-small-cell lung cancer with integrated positron-emission tomography and computed tomography. N Engl J Med 2003, 348:2500-2507.

53. Schoder $\mathrm{H}$, Larson SM, Yeung HW: PET/CT in oncology: integration into clinical management of lymphoma, melanoma, and gastrointestinal malignancies. J Nucl Med 2004, 45(Suppl 1):72S-81S.

54. Ahlstrom H, Malmstrom PU, Letocha H, Andersson J, Langstrom B, Nilsson S: Positron emission tomography in the diagnosis and staging of urinary bladder cancer. Acta Radiol 1996, 37:180-185.
55. Anjos DA, Etchebehere EC, Ramos CD, Santos AO, Albertotti C, Camargo EE: 18 F-FDG PET/CT delayed images after diuretic for restaging invasive bladder cancer. J Nucl Med 2007, 48:764-770.

56. Harkirat $\mathrm{S}$, Anand $\mathrm{S}$, Jacob M: Forced diuresis and dual-phase F-fluorodeoxyglucose-PET/CT scan for restaging of urinary bladder cancers. Indian I Radiol Imaging 2010, 20:13-19.

57. Kosuda S, Kison PV, Greenough R, Grossman HB, Wahl RL: Preliminary assessment of fluorine-18 fluorodeoxyglucose positron emission tomography in patients with bladder cancer. Eur J Nucl Med 1997, 24:615-620.

58. Vesselle HJ, Miraldi FD: FDG PET of the retroperitoneum: normal anatomy, variants, pathologic conditions, and strategies to avoid diagnostic pitfalls. Radiographics 1998, 18:805-823.

59. Liu IJ, Lai YH, Espiritu JI, Segall GM, Srinivas S, Nino-Murcia M, Terris MK: Evaluation of fluorodeoxyglucose positron emission tomography imaging in metastatic transitional cell carcinoma with and without prior chemotherapy. Urol Int 2006, 77:69-75.

60. Lu YY, Chen JH, Liang JA, Wang HY, Lin CC, Lin WY, Kao CH: Clinical value of FDG PET or PET/CT in urinary bladder cancer: a systemic review and meta-analysis. Eur J Radiol 2012, 81:2411-2416.

61. Bouchelouche K, Oehr P: Positron emission tomography and positron emission tomography/computerized tomography of urological malignancies: an update review. J Urol 2008, 179:34-45.

62. Oyen WJ, Bodei L, Giammarile F, Maecke HR, Tennvall J, Luster M, Brans B: Targeted therapy in nuclear medicine-current status and future prospects. Ann Oncol 2007, 18:1782-1792.

63. de Jong IJ, Pruim J, Elsinga PH, Jongen MM, Mensink HJ, Vaalburg W: Visualisation of bladder cancer using (11)C-choline PET: first clinical experience. Eur J Nucl Med Mol Imaging 2002, 29:1283-1288.

64. Gofrit ON, Mishani E, Orevi M, Klein M, Freedman N, Pode D, Shapiro A, Katz R, Libson E, Chisin R: Contribution of 11C-choline positron emission tomography/computerized tomography to preoperative staging of advanced transitional cell carcinoma. J Urol 2006, 176:940-944.

65. Picchio M, Treiber U, Beer AJ, Metz S, Bössner P, van Randenborgh H, Paul R, Weirich G, Souvatzoglou M, Hartung R, Schwaiger M, Piert M: Value of 11C-choline PET and contrast-enhanced CT for staging of bladder cancer: correlation with histopathologic findings. J Nucl Med 2006 , 47:938-944

66. Jana S, Blaufox MD: Nuclear medicine studies of the prostate, testes, and bladder. Semin Nucl Med 2006, 36:51-72.

67. DeGrado TR, Baldwin SW, Wang S, Orr MD, Liao RP, Friedman HS, Reiman R, Price DT, Coleman RE: Synthesis and evaluation of (18)F-labeled choline analogs as oncologic PET tracers. J Nucl Med 2001, 42:1805-1814.

68. Kruger S, Buck AK, Mottaghy FM, Hasenkamp E, Pauls S, Schumann C, Wibmer T, Merk T, Hombach V, Reske SN: Detection of bone metastases in patients with lung cancer: 99mTc-MDP planar bone scintigraphy, 18 F-fluoride PET or 18 F-FDG PET/CT. Eur J Nucl Med Mol Imaging 2009, 36:1807-1812

69. Even-Sapir E, Metser U, Mishani E, Lievshitz G, Lerman H, Leibovitch I: The detection of bone metastases in patients with high-risk prostate cancer: 99mTc-MDP planar bone scintigraphy, single- and multi-field-of-view SPECT, 18 F-fluoride PET, and 18 F-fluoride PET/CT. J Nucl Med 2006, 47:287-297.

70. Bouchelouche K, Capala J: 'Image and treat': an individualized approach to urological tumors. Curr Opin Oncol 2010, 22:274-280.

71. Zoller F, Eisenhut M, Haberkorn U, Mier W: Endoradiotherapy in cancer treatment-basic concepts and future trends. Euro J Pharmacol 2009, 625:55-62.

72. Rajjayabun PH, Keegan PE, Lunec J, Mellon JK: erbB receptor expression patterns in human bladder cancer. Urology 2005, 66:196-200.

73. Rotterud R, Nesland JM, Berner A, Fossa SD: Expression of the epidermal growth factor receptor family in normal and malignant urothelium. BJU Int 2005, 95:1344-1350.

74. Kramer-Marek G, Kiesewetter DO, Capala J: Changes in HER2 expression in breast cancer xenografts after therapy can be quantified using PET and (18)F-labeled affibody molecules. J Nucl Med 2009, 50:1131-1139.

75. Kramer-Marek G, Kiesewetter DO, Martiniova L, Jagoda E, Lee SB, Capala J: [18 F]FBEM-Z(HER2:342)-Affibody molecule-a new molecular tracer for in vivo monitoring of HER2 expression by positron emission tomography. Eur J Nucl Med Mol Imaging 2008, 35:1008-1018. 
76. Orlova A, Tran TA, Ekblad T, Karlstrom AE, Tolmachev V: (186)Re-maSGS-Z (HER2:342), a potential Affibody conjugate for systemic therapy of HER2-expressing tumours. Eur J Nucl Med Mol Imaging 2010, 37:260-269.

77. Tolmachev V, Orlova A, Pehrson R, Galli J, Baastrup B, Andersson K Sandström M, Rosik D, Carlsson J, Lundqvist H, Wennborg A, Nilsson FY: Radionuclide therapy of HER2-positive microxenografts using a 177Lu-labeled HER2-specific Affibody molecule. Cancer Res 2007, 67:2773-2782.

78. Judenhofer MS, Wehrl HF, Newport DF, Catana C, Siegel SB, Becker M, Thielscher A, Kneilling M, Lichy MP, Eichner M, Klingel K, Reischl G, Widmaier S, Röcken M, Nutt RE, Machulla HJ, Uludag K, Cherry SR, Claussen CD, Pichler BJ: Simultaneous PET-MRI: a new approach for functional and morphological imaging. Nat Med 2008, 14:459-465.

79. Pichler BJ, Kolb A, Nagele T, Schlemmer HP: PET/MRI: paving the way for the next generation of clinical multimodality imaging applications. J Nucl Med 2010, 51:333-336.

80. Delso G, Ziegler S: PET/MRI system design. Eur I Nucl Med Mol Imaging 2009, 36(Suppl 1):S86-S92.

81. Rioja J, Rodriguez-Fraile M, Lima-Favaretto R, Rincon-Mayans A, PenuelasSanchez I, Zudaire-Bergera JJ, Parra RO: Role of positron emission tomography in urological oncology. BJU Int 2010, 106:1578-1593.

doi:10.1186/1741-7015-11-104

Cite this article as: Hafeez and Huddart: Advances in bladder cancer imaging. BMC Medicine 2013 11:104

\section{Submit your next manuscript to BioMed Central and take full advantage of:}

- Convenient online submission

- Thorough peer review

- No space constraints or color figure charges

- Immediate publication on acceptance

- Inclusion in PubMed, CAS, Scopus and Google Scholar

- Research which is freely available for redistribution 